\title{
A special issue of Biophysical Reviews dedicated to the 20th IUPAB (virtual) Congress "in" Foz do Iguaçu
}

\author{
Rosangela Itri ${ }^{1} \cdot$ Mauricio Baptista ${ }^{2} \cdot$ Antonio José Costa-Filho $^{3} \cdot$ Richard Charles Garratt $^{4} \oplus$
}

Received: 6 November 2021 / Accepted: 8 November 2021 / Published online: 13 November 2021

(C) International Union for Pure and Applied Biophysics (IUPAB) and Springer-Verlag GmbH Germany, part of Springer Nature 2021

\begin{abstract}
The 20th IUPAB Congress took place online, together with the annual meetings of the Brazilian Biophysical Society and the Brazilian Society for Biochemistry and Molecular Biology, from the 4th to the 8th of October, 2021. The ten keynote lectures, 24 symposia, two poster sessions, and a series of technical seminars covered the full diversity of current biophysical research and its interfaces with other fields. The event had over 1000 attendees, with an excellent gender balance. Although the Americas dominated, there were also significant numbers of participants from Europe, Asia, and Africa.
\end{abstract}

The International Union of Pure and Applied Biophysics (IUPAB) came into existence in Stockholm in 1961 and has been a member of the International Science Council since 1966 (Solomon 1968). Its overall objectives aim to foster international collaboration in all aspects of biophysics and related areas and to catalyze the advancement of basic biophysical research as well as its many applications. Although IUPAB is active on many fronts, undeniably one of its showcase events is the IUPAB Congress, traditionally organized every three years in different locations worldwide. In 2021, the event was organized and run from Brazil, albeit for the very first time in a virtual format due to travel restrictions imposed by the COVID-19 pandemic. On this occasion, the Congress was organized in conjunction with the annual

Richard Charles Garratt

richard@ifsc.usp.br

Rosangela Itri

itri@if.usp.br

Mauricio Baptista

baptista@iq.usp.br

Antonio José Costa-Filho

ajcosta@ffclrp.usp.br

1 Institute of Physics, University of São Paulo, São Paulo, Brazil

2 Institute of Chemistry, University of São Paulo, São Paulo, Brazil

3 Ribeirão Preto School of Philosophy, Sciences and Literature, University of São Paulo, Ribeirão Preto, Brazil

4 São Carlos Institute of Physics, University of São Paulo, São Carlos, Brazil meetings of both the Brazilian Biophysical Society (SBBf, in its 45th edition) and the Brazilian Society for Biochemistry and Molecular Biology (SBBq, in its 50th edition). Even with the united forces of these well-established local societies, it turned out to be a bumpy ride to bring the event to fruition.

Plans for the 20th Congress began in 2016, almost immediately after the decision to hold the event in Brazil, a cause championed by the then-president of the Brazilian Biophysical Society, Marcelo Morales. The original plans had the meeting to be held in the Cidade Maravilhosa (The Wonderful City) of Rio de Janeiro in October 2020. However, it soon became apparent that the political and economic difficulties that the State of Rio was facing at the time meant that it would be wise to search for an alternative venue. The previous experience of SBBq in organizing similar events in the city of Foz do Iguaçu, on the borders with Argentina and Paraguay, made this an obvious choice. Furthermore, the natural attraction of the spectacular Iguaçu waterfalls seemed to be an ideal compensation for Sugar Loaf Mountain, Copacabana beach, and the statue of Christ the Redeemer on Corcovado Mountain.

Then came the pandemic. By mid-2020, it had become apparent that there were too many unknowns to make it possible to proceed with an in-person event in October of that year. It was decided to postpone the congress to 2021 but with a firm belief that things would be "back to normal." Sweet delusion! As 2020 turned into 2021 and the severity and longevity of the pandemic became clearer and clearer (not to mention the abysmal performance of the Brazilian government in failing to rise to the challenge), the inevitable 
decision was taken to transform the event into an "on-line" congress. This was a first for both the local organizers and the IUPAB.

The move to an online format immediately had an impact on the organization of the Young Scientist Program. This was initially envisaged to be a combination of formal and informal activities aimed at uniting about 40 early carrier scientists and post-docs for a couple of days prior to the main event in a stimulating atmosphere conducive to networking. Skillfully conceived, organized, and executed by Eneida de Paula (Campinas) and Eduardo Reis (São Paulo), this too had to be adapted to a "virtual reality." The successful solution turned out to be a series of fortnightly thematic webinars, including a talk from a recognized authority in the field followed by three or four short presentations from the participants themselves (Table 1). The standard was extremely high and the YSP ended up being a highly effective warm-up to the congress itself. Furthermore, there was excellent geographical diversity among the participants with Europe, Africa, Asia, the Middle East, and both North and South America represented.

The main event attracted over 1000 participants, with an excellent gender balance. Although the Americas dominated, there were also significant numbers of participants from Europe, Asia, and Africa (Fig. 1). Table 2 gives an excellent idea of the diverse subject matter covered during the 5 days of the congress itself. As to be expected, the way in which biophysics naturally interfaces with biochemistry, molecular biology, cell biology, chemistry (including medicinal chemistry), physics, engineering, etc. was more than apparent. Nevertheless, several themes appeared to be particularly recurrent throughout the event. Notwithstanding the plethora of other topics, several main threads permeated the proceedings, and these included (1) lipids, membranes, their assembly, and dynamics; (2) bioimaging at all levels; (3) drug targets and drug development/delivery; and (4) molecular recognition including membrane/protein interactions. This special issue aims to cover the main topics

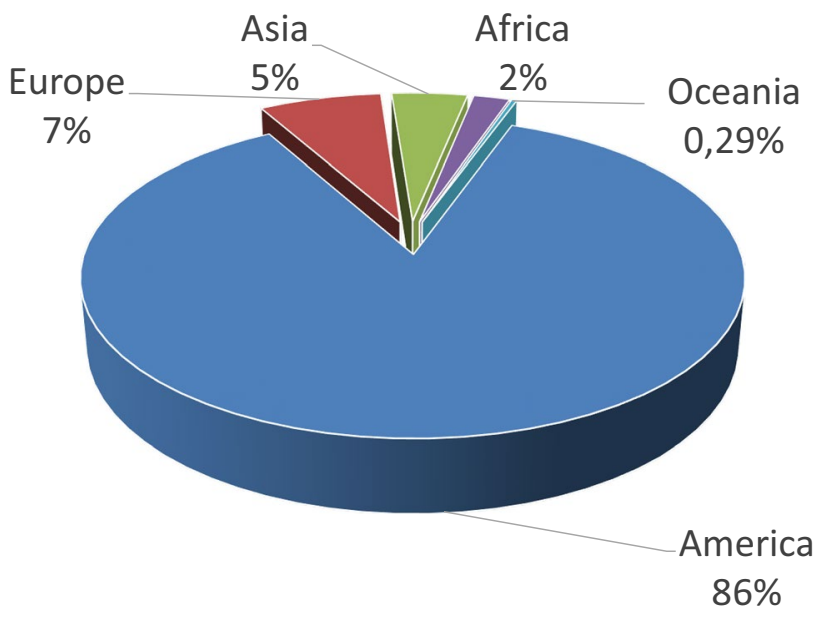

Fig. 1 Participants by continent

of the event as comprehensively as possible in similar vein to previous efforts (Hall and dos Remedios, 2017). In over 50 articles, including reviews, commentaries, letters, and editorials, we aim to convey the full flavor of the congress. It is hoped that this will serve simultaneously as both a useful source of reference and a historical record. The short, focused review articles are all up-to-date and expected to be of particular value to a broad readership. We hope that you enjoy them as much as we have and find them to be instructive and beneficial.

All of the Keynote lectures (Table 3) were very well attended. The Nobel laureate Richard Henderson set the ball rolling with a beautifully clear historical overview of how cryo-EM got to be where it is now and what we might expect for the near future. Tony Watts (the new presidentelect of IUPAB) closed the event with the Avanti/IUPAB award lecture and a clear message that biophysics is not all about proteins_-lipids are important (also)! Midweek, a second Nobel prize winner, Michael Levitt, gave his take on the COVID-19 pandemic by applying his talent
Table 1 Young Scientist Webinar Program

\begin{tabular}{|c|c|c|}
\hline Date & General subject area & Invited speaker \\
\hline 19th May & $\begin{array}{l}\text { Biomimetic Structures and Systems/Multiscale Bio- } \\
\text { physics of Membranes }\end{array}$ & Manuel Prieto, Portugal \\
\hline 26th May & Cell Biophysics and Phase Transition & Clifford Brangwynne, USA \\
\hline 9th June & Plant biotechnology/Biofuels/Bioenergy & Igor Polikarpov, Brazil \\
\hline 23rd June & Applications in Biomedical and Materials Science & - \\
\hline 7th July & Mechanisms of Membrane Protein & Natalie Strynadka, Canada \\
\hline 21st July & Membrane Permeation: Channels and Transporters & Eduardo Perozo, USA \\
\hline 4th August & Bioenergetics and Metabolism & Alicia Kowaltowski, Brazil \\
\hline 18th August & Protein Structure to Function/Structural Biology & Wah Chiu, USA \\
\hline 1st September & Computational Biophysics and Biochemistry & Ingemar André, Sweden \\
\hline 15th September & Drug Discovery and Delivery & Fabio Sonvico, Italy \\
\hline
\end{tabular}


Table 2 Symposia organized during the 20th IUPAB Congress

\begin{tabular}{|c|c|}
\hline Title & Chair \\
\hline Drug design and delivery & Joke Bouwstra (Leiden, Netherlands) \\
\hline Protein Structure, Dynamics and Function & Richard Garratt (São Carlos, Brazil) \\
\hline Biological Photosensors and their Applications in Optogenetics & Silvia Braslavsky (MPI, Germany) \\
\hline Macromolecular Machines and Switching Devices & Alejandro Buschiazzo (Montevideo, Uruguay) \\
\hline RSC-Chemical Biology & Randall Peterson (Utah, USA) \\
\hline Young Talent in Life Sciences (Cytiva Award) & Juliana Fietto (Viçosa, Brazil) \\
\hline Deforming Membranes & Patricia Bassereau (Curie Institute, France) \\
\hline Systems Biology and Biomarkers for Human Disorders & Peter Nilson (KTH, Stockholm, Sweden) \\
\hline PABMB Symposium: Metabolism and Bioenergetics & Alicia Kowaltowski (São Paulo, Brazil) \\
\hline Biophotonics & Georg Wondrak/Martha Ribeiro (Arizona, USA/São Paulo, Brazil) \\
\hline Microbiomes: human and environmental & Leda Vieira (Belo Horizonte, Brazil) \\
\hline Molecular and Cell Imaging & Paulo Bisch (Rio de Janeiro, Brazil) \\
\hline Ionic Channels and Membrane Transporters & John Baenziger (Chicago, USA) \\
\hline Biomolecular Association and Dynamics & Paul Whitford (Boston, USA) \\
\hline Gender in Science & $\begin{array}{l}\text { Cristina Nonato/David Crossman (Ribeirão Preto, Brazil/Aukland, } \\
\text { New Zealand) }\end{array}$ \\
\hline Protein Folding, Misfolding and Unfolding & Vladimir Uversky (Tampa, USA) \\
\hline EBSA Symposium on Translational Biophysics & Anthony Watts/Jesús Pérez-Gil (Oxford, UK/Madrid, Spain) \\
\hline Autophagy: Mechanisms and Applications & Marcelo Mori (Campinas, Brazil) \\
\hline Membrane Simulation & Mikko Karttunen (Ontario, Canada) \\
\hline Systems Biologics: at the interface... & Stephen Michnick (Montreal, Canada) \\
\hline IUBMB Symposium: Science Education & Manuel João Costa (U. Minho, Portugal) \\
\hline Scissioning Membranes & Rumiana Dimova (Potsdam, Germany) \\
\hline Redox Biology & Rafael Radi (Montevideo, Uruguay) \\
\hline Biophysics of the Immune System & Jean-Marie Ruysschaert (Brussels, Belgium) \\
\hline
\end{tabular}

Table 3 Keynote speakers

\begin{tabular}{|c|c|}
\hline Speaker & Title \\
\hline Richard Henderson (LMB, Cambridge) & Impact of Single Particle Cryo-electron Microscopy on Structural Biology \\
\hline $\begin{array}{l}\text { Carlos Bustamante (University of Cali- } \\
\text { fornia, Berkeley) }\end{array}$ & $\begin{array}{l}\text { Co-temporal Force and Fluorescence Measurements Reveal a Ribosomal Gear-shift Mechanism of } \\
\text { Translation Regulation by mRNA Secondary Structures }\end{array}$ \\
\hline $\begin{array}{l}\text { Giorgio Trinchieri (Center for Cancer } \\
\text { Research, NIH, Maryland) }\end{array}$ & Targeting the microbiome in cancer immunotherapy \\
\hline Tao Xu (Chinese Academy of Sciences) & $\begin{array}{l}\text { The Bei Shizhang Lecture: Cryogenic superresolution correlative light and electron microscopy on } \\
\text { the frontier od subcellular imaging }\end{array}$ \\
\hline Michael Levitt (Stanford) & Lessons from 620 days Studying COVID-19 \\
\hline Ohara Augusto (São Paulo) & Carbon Dioxide Redox Metabolites in Eustress and Oxidative Distress \\
\hline Ramon Latorre (Valparaíso) & Calcium-driven Voltage Sensingand the role of Charged Residues in the voltage sensor domain of BK \\
\hline Angela Gronenborn (Pittsburgh) & The Awesome Power of Fluorine NMR \\
\hline Yoav Shechtman (Haifa) & $\begin{array}{l}\text { IUPAB Young Investigator Lecture: Next Generation Localization Microscopy—or How and Why } \\
\text { to Ruin and Perfectly Good Microscope }\end{array}$ \\
\hline Anthony Watts (Oxford) & Avanti/IUPAB Award Lecture: Lipids are important \\
\hline
\end{tabular}

for mathematical modeling in much the same way as he so successfully applied it to macromolecular systems in the past. At the very least, his talk gave plenty of food for thought to those who were present.
Overall, the sessions were very well attended with typically over 200 participants. The ease of moving from one session to another under the virtual format proved to be a notable advantage. Furthermore, since many of 
the talks were pre-recorded, most of the sessions kept to time rather better than is often the case at traditional events. The two poster sessions were also very well frequented, and the pre-recorded videos were generally of high quality. Approximately $10 \%$ of all poster presenters were awarded prizes during the closing ceremony, and six special prizes were generously provided by the Royal Society of Chemistry.

Several special activities were held throughout the week. These included technical seminars by some of the sponsors, including Cytiva, Thermo-Fisher, and Sartorius as well as sessions devoted to Brazil-German exchange programs and one on "Gender in Science." The latter was particularly motivational for the congress participants, whose demographic was heavily biased towards earlycareer scientists, post-docs, and students (Fig. 2). Biophysical Reviews organized two early-morning sessions, one of which was an editorial board meeting whilst the other was open to all interested parties and represented an opportunity to promote the journal within the community. The IUPAB held its general assembly on the 6th of October. Manuel Prieto formally took over as President with Marcelo Morales stepping down but continuing as a council member in the role of immediate Past President. Tony Watts becomes the new President Elect.

Despite the challenges of organizing a widely diverse international event online, we came away with the feeling of a mission accomplished and the hope that we will be able to meet up in person in the very near future. From the extremely high standard of the presentations and the overall satisfaction of the participants, we think it can be considered to have been a success. See you all in Kyoto!

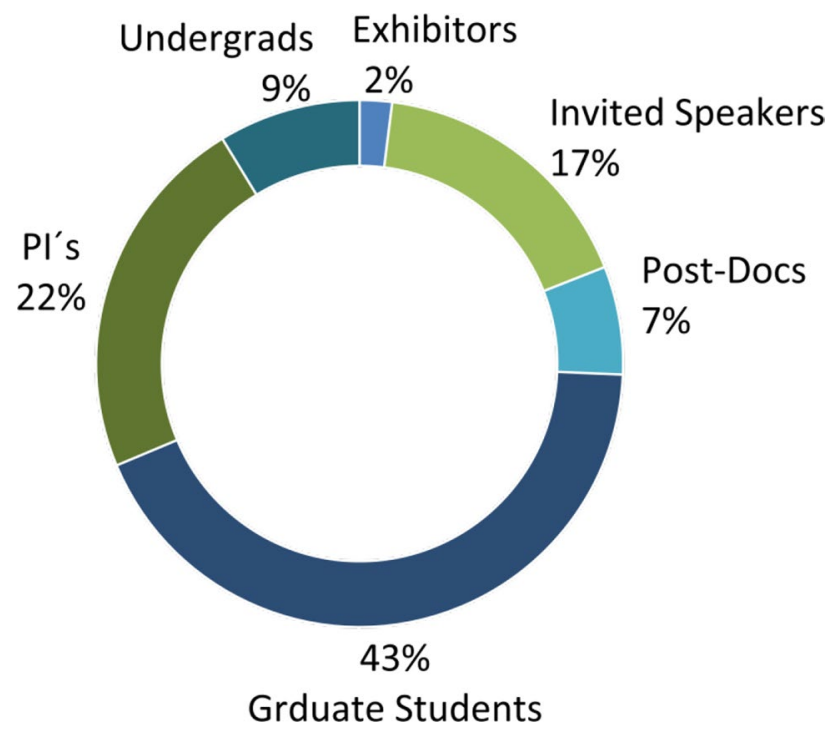

Fig. 2 The distribution of participants according to their stage in the career

\section{Biosketches}

Rosangela Itri: holds a BSc in Physics from the Pontificea Universidade Católica, São Paulo, and did her PhD degree in solid-state physics at the Physics Institute of the University of São Paulo (IFUSP), Brazil. Her post-graduate studies focused on colloidal particles and liquid-crystal systems using small angle X-ray scattering (SAXS). She has spent her entire professional career at IFUSP since 1992, where she is currently a full professor. After her $\mathrm{PhD}$, she started to develop an interest in biological systems and invested a lot of effort in working out how to apply her background expertise in SAXS to better understand biologically relevant problems. With this in mind, she undertook a 1-year sabbatical in 1994 at the Chemistry Institute at Ohio State University in order to better learn how to work with protein/multilayered membrane interaction using the X-Ray standing-wave method. When she returned to IFUSP, she established the Biophysics Laboratory at the Applied Physics Department, and began to cultivate a close collaboration with colleagues from the Biochemistry Department in a multidisciplinary approach. She expanded her experimental horizons by combining SAXS with spectroscopic techniques and implementing studies of giant unilamellar vesicles, as model lipid membranes, using optical phase contrast and fluorescence microscopy. Currently, her main research interests are (i) the synthesis and characterization of biomaterials including guanosinebased hydrogels, (ii) protein conformation and interaction, (iii) lipid photo-oxidation promoting membrane damage, and (iv) membrane fission induced by photo-oxidation and amphipathic molecules.

Mauricio Baptista: Mauricio S. Baptista is a full professor and head of the Department of Biochemistry at the University of São Paulo. He graduated in Pharmacy and Biochemistry from the University of São Paulo (1990), has a master's degree in Biological Sciences (Biochemistry) from the University of São Paulo (1992), and obtained his PhD from Marquette University, USA (1996). He did a post-doctorate at UW-Madison, School of Pharmacy, USA (1997), and was a visiting professor at the Université Joseph Fourier in 2006. He serves as co-editor in chief of the Journal of Photochemistry and Photobiology B: Biology (Elsevier) and is a member of the editorial board of the magazine Scientific Reports (Nature). He is a member of the São Paulo State Academy of Sciences, of the Brazilian Societies of Biochemistry and Molecular Biology, of Chemistry, and of Biophysics and is a board member of the American Society of Photobiology (ASP). His current research interests are photochemistry and photobiology of the skin, photodynamic therapy, redox processes, and regulated mechanisms of cell death.

Antonio José Costa-Filho: received a Bachelor's (1994) and a Master's (1996) degree in Physics from the 
University of São Paulo. He undertook his $\mathrm{PhD}$ project in São Carlos and in Ithaca (USA), where he was a graduate student at Cornell University, working under Prof. Jack Freed's supervision. During his PhD, he worked on the development of new electron magnetic resonance methods for the study of (1) lipid-protein interactions, (2) the dynamic structure of lipid membranes, and (3) metal centers in proteins. In 2001, he received his $\mathrm{PhD}$ degree in Physics from the University of São Paulo and started working as an Assistant Professor at USP (Campus São Carlos) and is currently a full professor at the Campus in Ribeirão Preto. His research interests involve investigating interactions between biomolecules, emphasizing that the interaction between proteins and their ligands (substrates, inhibitors, and membranes) can lead to modulation of the protein's function. More recently, he also became interested in the structural behavior of proteins involved in the unconventional secretory pathways of the cell, in particular, the so-called Golgi Reassembly and Stacking Proteins (GRASPs). His group uses an interdisciplinary approach and a combination of experimental techniques, such as magnetic resonance, circular dichroism, fluorescence, and microcalorimetry, to accomplish these objectives. He has received several awards for his teaching skills. He is a Young Affiliate Alumnus of the Brazilian Academy of Sciences and the World Academy of Sciences (TWAS), coordinator of the Advisory Committee of the Brazilian National Science Foundation (CNPq) on Biophysics/Biochemistry/Physiology/Pharmacology/Neurosciences, past president of the Brazilian Biophysical Society, and director of the Ribeirão Preto Institute for Advanced Studies of the University of São Paulo.

Richard Charles Garratt: has been on the academic staff of the São Carlos Institute of Physics since 1992. As a biological scientist by training, he is almost unique in Brazil for holding the position of full professor in a physics department. His post-graduate training was undertaken in crystallography and allied spectroscopic techniques at Birkbeck College in London during the 1980s. He subsequently moved to the University of São Paulo in 1989 where he was instrumental in establishing the first protein crystallography laboratory in Brazil and possibly Latin America. He also actively participated in the proposal which led to the construction of the first protein crystallography synchrotron radiation beamline in the southern hemisphere. His interests span many aspects of structural biology but principally the use of protein crystallography (and more recently cryo-EM) in the understanding of a wide range of biological phenomena at the molecular level. He has worked on glycolytic enzymes, superoxide dismutases, purine salvage enzymes, lectins, giant hemoglobins, and more recently on filamentforming GTPases known as septins. Work on the fatty-acid transport molecule Sm14 from the blood fluke has led to the most promising human vaccine candidate for a helminth so far developed. Furthermore, his interests in the teaching of structural biology have led to the development of pedagogical aids including unique physical cartoon-style models and a "periodic table" of domain folds (The Protein Chart). $\mathrm{He}$ is an active member of CeBEM (The Structural Biology Center of the Mercosul) which promotes the growth of structural biology in South America. He has held honorary positions at King's College, London (Guy's Hospital), and the University of Liverpool. He is a member of the Brazilian Academy of Sciences and holds honorary doctorates from two Peruvian universities.

\section{Declarations}

Conflict of interest The authors declare that no competing interests.

\section{References}

Hall D, dos Remedios CG (2017) Special Issue of Biophysical Reviews dedicated to the $19^{\text {th }}$ IUPAB Conference in Edinburg Scotland. Biophys Rev 9:269-271. https://doi.org/10.1007/ s12551-017-0312-4

Solomon AK (1968) A short history of the foundation of the international union for pure and applied Biophysics. Q Rev Biophys 1:107-124. https://doi.org/10.1017/S0033583500000482

Publisher's Note Springer Nature remains neutral with regard to jurisdictional claims in published maps and institutional affiliations. 